\title{
Reduction of Blood Loss During Laparoscopic Myomectomy: Uterine Artery Ligation Versus Intra-Vaginal Misoprostol
}

\author{
Ahmed Nofal*, Dalia Ibrahim and Hesham Ammar \\ Department of Obstetrics and Gynecology Faculty of Medicine, Menoufia University, Egypt
}

Submission: November 19, 2018, Published: September 06, 2019

*Corresponding author: Ahmed Nofal, Department of Obstetrics and Gynecology Faculty of Medicine, Menoufia University, Shibin El-Kom City, Menoufia governorate, Egypt

\section{Abstract}

Objectives: This study was designed to compare laparoscopic uterine artery ligation and vaginal misoprostol in reducing intra-operative blood loss during laparoscopic myomectomy and verifies the effect of uterine artery ligation by different methods upon intra- and post-operative complications of laparoscopic myomectomy.

Background: laparoscopic myomectomy is a challenging surgical procedure for gynecologists. Material and Methods: The study was prospective clinical randomized trial, where 50 women with symptomatic fibroids managed with laparoscopic myomectomy with either bilateral uterine artery ligation or pre-operative misoprostol, outcome parameters in both groups were operative time, blood loss during surgery, fluid management data and post-operative period. Statistical presentation and analysis of the present study was conducted with SPSS V.20

Results: a total of 50 patients of these 30 patients underwent laparoscopic myomectomy and bilateral uterine artery ligation and 20 underwent laparoscopic myomectomy after preoperative vaginal misoprostol the mean intra operative blood loss was $522.5+136.6$ versus 193.8+78.7 in misoprostol versus UAL groups and there was a highly significant difference between the two groups as regarding blood loss (less in UAL group), also there was significant as regarding operative time (longer in UAL group).There was no significant difference as regarding intraoperative complications and post-operative period.

Conclusion: Bilateral ligation of uterine artery has a more powerful effect than preoperative single dose of misoprostol in reducing blood loss during laparoscopic myomectomy, but bilateral ligation of uterine artery takes a longer time however no significant difference between them as regarding post-operative complications.

Keywords: Angiogenesis, Blood loss, Laparoscopic myomectomy, Misoprostol, Uterine artery ligation

\section{Introduction}

Myomectomy, as an optimal treatment for symptomatic uterine myomas that can avoid hysterectomy and preserve fertility. Studies showed that there is shrinkage of very small fibroids that were not removed during the surgery, which prevents recurrence of new fibroids [1,2]. Laparoscopic ligation of uterine arteries has been combined with myomectomy, with successful reduction in blood loss [3]. Misoprostol is a prostaglandin E1 analogue that is rapidly absorbed. Misoprostol has the advantage of being inexpensive and stable at room temperature [4]. The preoperative use of misoprostol in patients with uterine fibroids significantly reduces intraoperative blood loss. Prostaglandins cause the myometrium and isolated uterine arteries to contract [5].
Subject and methods the study was prospective clinical randomized trial. Randomization was done via reshuffled approach with the shuffled cards in ratio of 3:2 (uterine artery ligation: insertion of misoprostol) respectively. The study was conducted during the period from 2013 to 2016 in Endoscopy unit of Obstetrics and Gynecology Department at Cairo University hospitals, Egypt. All women were counseled for risks and benefits of laparoscopic myomectomy and uterine artery ligation and the need for cesarean section in future deliveries. Then all patients signed an informed written consent approved by Ethical Committees of Faculty of Medicine, Menoufia University and Cairo University before surgery. The study involved 50 women with abnormal uterine bleeding or infertility due to uterine fibroid. 
Inclusion criteria were Fibroid uterus: number 1 to $3 \mathrm{my}$ omas, size less than $8 \mathrm{~cm}$ diagnosed by ultrasound, age: $20-35$ years, non-hypertensive patients and no contraindications for laparoscopic surgery such as cardiac diseases and restrictive lung diseases. Exclusion criteria were History of previous myomectomy or abdominal surgery, preoperative (within 3 months) hormonal therapy ( $\mathrm{GnRH}$, oral contraceptive pills, progestin releasing intrauterine device), cervical fibroids, multiple fibroids more than 3 , size of uterus more than 20 weeks, surgically unfit women (bleeding tendency and contraindication to general anesthesia) and adenomyosis, endometriosis and other ovarian pathologies. All participants were subjected to thorough personal, obstetric and gynecological history including history of previous hormonal treatment in the last 3 months, thorough clinical examination: general, abdominal and local examination to diagnose size and mobility of uterus, investigations: routine preoperative investigations including $\mathrm{Hb}$ and Hematocrit levels before and after surgery, ultrasound examination to assess size, site, volume and number of fibroids and preoperative hysterosalpingography to confirm tubal patency in infertile patients.

They were divided into two groups Group 1

\section{Uterine artery ligation group}

a. women in whom uterine artery ligation was done by either

b. Bilateral uterine artery ligation by clamps (bull dog vascular clamp, manufactured by Aesculap, USA): The triangle enclosed by the round ligament, external iliac vessels and infundibulopelvic ligament opened 2 to $3 \mathrm{~cm}$ with scissors and the lateral umbilical fold was identified then dissecting cephalad was done where the uterine artery was identified originating from internal iliac artery isolation and ligation of uterine artery with a single bulldog clip using hemostat vascular clip applicator. At the end of the procedure the clips were released and removed out of abdomen.

c. Bilateral uterine artery ligation by tourniquet technique: A pediatric Foley's catheter $(6 \mathrm{~F}$, manufactured by
Euro med company, Egypt.) was introduced to the abdomen through trocar incision site then passed through defects made in broad ligament on both sides of the uterus by scissors. Ligation of the catheter around the uterus was done with tightening of the catheter to compress both uterine arteries in order to close uterine blood flow. At the end of the myomectomy, the catheter was released and removed out of the abdomen.

\section{Group 2: Misoprostol group 2:}

This group included 20 patients in whom 400 ug misoprostol (two tablets) (misotacR manufactured by Sigma company, Egypt.) were Inserted vaginally at night before surgery.

At the end of the study, the data collected were tabulated and analyzed by SPSS V.20 (statistical package for the social science software) .The results were expressed by applying ranges, means \pm S.D., X2 (Chi-square test), T test, U (Mann Whitney test), $\mathrm{R}$ (person correlation coefficient )t, Ficher exact test and $\mathrm{P}$ value. $\mathrm{P}$ value $<0.05$ was considered to be significant, $\mathrm{P}$ value $<0.001$ was considered statistically highly significant.

\section{Results}

The study showed that there was no significant difference between the two groups as regard age, BMI, parity, size, site, number of myomas and clinical presentation ( $\mathrm{P}$ value $=0.07$ ) as shown in (Table 1). There was a highly significant difference (P value $=0.0009$ ) between the two groups as regarding operative time (longer in UAL group), also there was statistical significance as regarding estimated blood loss (less in UAL group) There was insignificant statistical difference between the two groups as regarding preoperative and postoperative fluid intake (Table 2). Also there was insignificant difference between the two groups as regarding preoperative $\mathrm{Hb}$ and Hct but there was significant difference between them as regarding postoperative $\mathrm{Hb}$ and $\mathrm{Hct}$ levels (Table 3). There was no significant difference between the two groups concerning post operative duration of care till discharge, post-operative pain and post-operative fever and blood transfusion (Table 4,5).

Table 1: Demographic criteria of the studied patients.

\begin{tabular}{|c|c|c|c|c|c|c|}
\hline & \multicolumn{2}{|c|}{ Misoprostol Group $\mathrm{N}=20$} & \multicolumn{2}{|c|}{ UA Occlusion $\mathrm{N}=30$} & T Test & P Value \\
\hline Age (year) & \multicolumn{2}{|c|}{$28.9 \pm 4.4$} & \multicolumn{2}{|c|}{$28.1 \pm 5.1$} & 0.572 & 0.57 \\
\hline BMI $\left(\mathrm{kg} / \mathrm{m}^{2}\right)$ & \multicolumn{2}{|c|}{$24.1 \pm 3$} & \multicolumn{2}{|c|}{$23.3 \pm 2.6$} & 1.03 & 0.307 \\
\hline Gravidity & \multicolumn{2}{|c|}{$1.8 \pm 1.1$} & \multicolumn{2}{|c|}{$2 \pm 1.2$} & $0.729^{*}$ & 0.47 \\
\hline Myoma diameter $(\mathrm{cm})$ Mean \pm SD Range & \multicolumn{2}{|c|}{$5.25 \pm 1.5$} & \multicolumn{2}{|c|}{$5.5 \pm 1.73-7$} & 1.71 .1 & 0.090 .271 \\
\hline Volume of the uterus $\left(\mathrm{cm}^{3}\right)$ & \multicolumn{2}{|c|}{$400 \pm 93.6$} & \multicolumn{2}{|c|}{$416.7 \pm 108.7$} & 0.561 & 0.578 \\
\hline Weight of the removed myomas(gm) & \multicolumn{2}{|c|}{$294.5 \pm 86.8$} & \multicolumn{2}{|c|}{$307.3 \pm 99.4$} & 0.47 & 0.641 \\
\hline Clinical presentation AUB Infertility & \multicolumn{2}{|c|}{$15(75 \%) 5(25 \%)$} & \multicolumn{2}{|c|}{$21(70 \%) 9(30 \%)$} & $0.149^{* *}$ & 0.7 \\
\hline Tumour type Intramural Subserous & \multicolumn{2}{|c|}{$16(80 \%) 4(20 \%)$} & \multicolumn{2}{|c|}{$27(90 \%) 3(10 \%)$} & $0.997^{* * *}$ & 0.318 \\
\hline Number of myomas Single Double & \multicolumn{2}{|c|}{$16(80 \%) 4(20 \%)$} & \multicolumn{2}{|c|}{$23(76.7 \%) 7(23.3 \%)$} & $0.078^{* * *}$ & 0.78 \\
\hline \multirow{2}{*}{ Pre operative HSG } & \multicolumn{2}{|c|}{ Misoprostol group } & \multicolumn{2}{|c|}{ UA occlusion } & \multirow{2}{*}{$\mathrm{X}^{2}$} & \multirow{2}{*}{$P$ value } \\
\hline & $\mathrm{N}=5$ & $\%$ & $\mathrm{~N}=9$ & $\%$ & & \\
\hline
\end{tabular}


Journal of Gynecology and Women's Health

\begin{tabular}{|c|c|c|c|c|c|}
\hline Normal & 2 & 40 & 9 & 100 & \\
\cline { 1 - 4 } Lt tubal block & 1 & 20 & 0 & 0 & \multirow{2}{*}{0.9} \\
\cline { 1 - 5 } Rt tubal block & 2 & 40 & 0 & 0 & \\
\hline
\end{tabular}

*U test (Mann Whitney test)

${ }^{* *}$ X2 (Chi-square test)

${ }^{* * *}$ Ficher exact test

Table 2: Operative time and mean blood loss in both groups

\begin{tabular}{|c|c|c|c|c|}
\hline & Misoprostol Group $\mathrm{N}=\mathbf{2 0}$ & UA Occlusion $\mathrm{N}=\mathbf{3 0}$ & T Test & P Value \\
\hline Operative time(min) Mean \pm SD Range & $90.5 \pm 7.170-100$ & $107.6 \pm 13.290-150$ & 5.3 & $<0.001$ \\
\hline Introperative fluid intake $(\mathrm{ml})$ Mean \pm SD Range & $1350 \pm 6501000-1500$ & $1500 \pm 5001000-2000$ & 1.6 & 0.112 \\
\hline Postoperative fluid intake(ml) Mean \pm SD Range & $750 \pm 250500-1000$ & $660 \pm 340500-1000$ & 1.57 & 0.124 \\
\hline Estimated blood loss(ml) & $522.5 \pm 136.6350-760$ & $193.8 \pm 78.790-300$ & $10.8^{*}$ & $<0.001$ \\
\hline
\end{tabular}

*U test (Mann Whitney test)

Table 3: Pre and post-operative haematinic indicies in both groups.

\begin{tabular}{|c|c|c|c|c|}
\hline & Misoprostol Group N=20 & UA Occlusion N=30 & T Test & P Value \\
\hline Preoperative Hb(gm/dl) Mean \pm SD Range & $12.1 \pm 0.511-13$ & $12.1 \pm 0.311-13$ & 0.425 & 0.673 \\
\hline Postoperative Hb(gm/dl) Mean \pm SD Range & $10.7 \pm 0.69 .5-11.7$ & $11 \pm 0.410 .3-11.9$ & 2.3 & 0.026 \\
\hline Pre operative hct Mean \pm SD Range & $36.3 \pm 1.633-39$ & $36.2 \pm 133-39$ & 0.425 & 0.673 \\
\hline Post operative hct Mean \pm SD Range & $32.1 \pm 0.1828 .5-35.1$ & $33 \pm 1.230 .9-35.7$ & 2.3 & 0.026 \\
\hline
\end{tabular}

Table 4:Post operative duration of care till discharge.

\begin{tabular}{|c|c|c|c|c|c|c|}
\hline \multirow{2}{*}{ Discharge Time } & \multicolumn{2}{|c|}{ Misoprostol Group } & \multicolumn{2}{|c|}{ UA Occlusion } & \multirow{2}{*}{$\mathrm{X} 2$} & \multirow{2}{*}{ P Value } \\
\hline & $\mathrm{N}=\mathbf{2 0}$ & $\%$ & $\mathrm{~N}=30$ & $\%$ & & \\
\hline Day of operation ( Day 0 ) & 16 & 80 & 26 & 86.7 & \multirow{3}{*}{1.6} & \multirow{3}{*}{0.452} \\
\hline 1day after & 3 & 15 & 4 & 13.3 & & \\
\hline 2 days after & 1 & 5 & 0 & 0 & & \\
\hline
\end{tabular}

Table 5:Post-operative pain.

\begin{tabular}{|c|c|c|c|c|c|c|}
\hline \multirow{2}{*}{ Complications } & \multicolumn{2}{|c|}{ Misoprostol Group } & \multicolumn{2}{|c|}{ UA Occlusion } & \multirow{2}{*}{$\mathrm{X} 2$} & \multirow{2}{*}{ P Value } \\
\hline & $\mathrm{N}=\mathbf{2 0}$ & $\%$ & $\mathrm{~N}=\mathbf{3 0}$ & $\%$ & & \\
\hline Pain (Mild) & 10 & 50 & 12 & 40 & \multirow{3}{*}{3.8} & \multirow{3}{*}{0.147} \\
\hline Pain (Moderate) & 5 & 25 & 15 & 50 & & \\
\hline Pain (Severe) & 5 & 25 & 3 & 10 & & \\
\hline None & 17 & 85 & 28 & 93.3 & \multirow{5}{*}{1.06} & \multirow{5}{*}{0.587} \\
\hline Fever & 2 & 10 & 1 & 3.3 & & \\
\hline Blood transfusion & 1 & 5 & 1 & 3.3 & & \\
\hline Visceral injuries & 0 & 0 & 0 & 0 & & \\
\hline Mortality & 0 & 0 & 0 & 0 & & \\
\hline
\end{tabular}

\section{Discussion}

The current study has shown that UAL is more effective than misoprostol in reducing blood loss during myomectomy where, the mean intraoperative blood loss was $522.5 \pm 136.6 \mathrm{ml}$ in misoprostol group versus $213.2 \pm 120.2 \mathrm{ml}$ in UAL group, where there was a highly significant statistical difference between the two groups ( $\mathrm{p}=0.0009$ ). However there a longer operative time in UAL group 90.5+7.1 min versus $107.6+13.2 \mathrm{~min}$ in misoprostol and UAL groups respectively ( $\mathrm{p}$ value $=0.0009$ ). A number of studies have shown that temporary uterine artery ligation during laparoscopic myomectomy had reduced intraoperative blood loss.

Temporary uterine artery ligation was reported [5-9].did his study on 166 patients of whom 80 underwent temporary uterine artery clipping and myomectomy while the other 86 underwent myomectomy only, there were statistical significant difference in blood loss between the two groups (less in UAL group). The study done by [7] demonstrated that temporary clipping of the uterine artery during myomectomy had reduced blood loss during the 
procedure, also a study [8] showed that uterine artery clipping by bulldog clip might be an effective, safe and reliable method for reducing bleeding during laparoscopic myomectomy and didn't lead to persistent damage to the uterine artery.

Another study by [9] included 20 women with uterine fibroid underwent laparoscopic myomectomy and UAL with a ligating clip followed by myomectomy and removal of clips showed that intra operative blood loss in UAL group was statistically significant less than the control group. Some studies had reported that the preoperative use of misoprostol before laparoscopic myomectomy had significant reduction of intraoperative blood loss as $[10,11,12]$. Stated that preoperative insertion of $800 \mathrm{mg}$ of misoprostol rectally showed significant reduction in the blood flow of the segmental branch of the uterine artery and those supplying fibroids and so significant reduction in intraoperative blood loss [11]. concluded that preoperative use of 200 ug misoprostol vaginally led to significant difference in blood loss between the two groups (less in misoprostol group) [12]. Study, showed that the mean blood loss with vaginal misoprostol had statistically significant reduction than in placebo group.

However, some studies did not conclude significant reduction of intraoperative blood loss such as in [13] study. In [13] study, a permanent UAL was performed using a Liga Sure (Valley lab, Boulder, CO) or bipolar coagulator and this study concluded that there was no significant difference between the two groups(LM with uterine artery ligation) group and (LM without uterine artery ligation) as control group, regarding to the intra operative blood loss. In this study there was significant difference between the two groups in pre and post-operative $\mathrm{Hb}$ and Hct $(\mathrm{p}=0.026)$ where the post-operative $\mathrm{Hb}$ and Hct was higher in UAL groups. A study by [6] found that there was significant difference between the experimental (UAL) and control groups as regarding hemoglobin change. In experimental group the mean drop in $\mathrm{Hb}$ in day 1 was1.2 gm/dl and in control group was $1.45 \mathrm{gm} / \mathrm{dl}$. Also [11] study showed that there was significant difference between the two groups with respect to the hemoglobin change post-operatively.

However, in [13] study. There were no significant differences between the two groups with respect to the post-operative hemoglobin reduction. In the current study, the omission of technical aspect of uterine artery ligation in misoprostol group had led to high statistically significant shorter operative time in that group compared with UAL group (the mean operating time was $90.5 \pm 7.1$ minutes in misoprostol group versus $107.6 \pm 13.2 \mathrm{~min}-$ utes in UAL group) with ( $\mathrm{p}=0.0009)[9]$. study stated that there was statistically significant longer operative time in UAL than in control group. Also [14] study showed that mean operative time was statistically significant more in LM with LUAD than in LM alone.

Another study by [6] concluded that the time needed to put clip in place was 6-40 min. (longer than control group, ( $p$ value $=0.0004)$. Other studies as $[9,15]$ supported this opinion (UAL needed significant longer time than LM alone). In another study by [11] there was significant difference in operative time between misoprostol group and placebo group (shorter in misoprostol group). However, in [13] there was no statistical significant difference between UAL groups versus control group. The mean time for bilateral UAL was $6.7 \pm 1.5$ minutes. In this study, the mean hospital stay was $0.4 \pm 0.1$ days after operation in both groups, in [13] the mean hospital stay was $3.9 \pm 0.9$ days in UAL group and $4.1 \pm 0.9$ days in control group. In [9] study the post-operative hospital stay was 3 days, in [14] study, the mean post-operative hospital stay was 2.6 vs. 2.1 days in UAL group and control group respectively. The total conversion rate into laparotomy in the current study was $4 \%$ with no statistical difference in conversion rate in both groups. In [13] there were no conversion to laparotomy in the two groups, also in [6] study no patient had converted to laparotomy. In [16] study the conversion rate was $15 \%$ and this was in the beginning of the study due to lack of experience.

The total complication rate of the present study had no significant statistical difference in both groups.

In the current study the incidence of blood transfusion was $5 \%$ versus $3.3 \%$ in misoprostol versus UAL group with no statistical significance between the two groups. In [15] study $17.2 \%$ of the control group required blood transfusion but no case required blood transfusion in the experimental group, while in $[6,13]$ studies there were no cases required blood transfusion and in [11] the need for postoperative blood transfusion was significantly lower in misoprostol group; nine patients in control group needed blood transfusion while no one needed blood transfusion in misoprostol group. In [16] study the incidence of blood transfusion was necessary in $7 \%$ of patients the day after surgery.

In this study the febrile morbidity rate was $10 \%$ versus $3.3 \%$ in misoprostol versus UAL group, in [13] study no febrile morbidity in the two groups, in [15] study febrile morbidity occurred in $18.5 \%$ in experimental group and in $20.7 \%$ in control group. In the current study there was statistically significant positive correlation between tumor size and the operative time in both groups, [17] study revealed that the total operative time was significantly affected by the size of tumor. In this study there was no significant difference as regarding to postoperative pain in the two groups. A limitation to this research was small number of patients, and inability to include a control group. Points of strength in this research, being prospective and comparative in nature, included two groups and conducted in a university hospital with expert laparoscopic surgeon.

\section{Conclusion}

Bilateral ligation of uterine artery has a more powerful effect than preoperative single dose of misoprostol in reducing blood loss during laparoscopic myomectomy. However, UAL takes lon- 
ger time with no significant difference between them regarding post-operative complications.

\section{References}

1. Dubuisson B, Fauconnier A, Fourchotte V, Babaki-Fard K, Coste J, et al. (2001) Laparoscopic myomectomy: predicting the risk of conversion to an open procedure. Hum Reprod 16(8): 1726-1731.

2. Lichtinger M, Burbank F, Hallson L, Herbert S, Uyeno J, et al. (2003) The time course of myometrial ischemia and reperfusion after laparoscopic uterine artery occlusion-Theoretical implications. J Am Assoc Gynecol Laparosc 10(4): 553-563.

3. Liu WM, Tzeng CR, Yi-Jen C ,Wang PH (2004) Combining of the uterine depletion procedure and myomectomy may be useful for treating symptomatic fibroids. Fertil Steril 82(1): 205-210.

4. Shabana A, Kilani EO, Khouly EN, Shereen M (2015) Comparison of oral misoprostol and oxytocin for labor induction in prelabor rupture of membranes at term. Menoufia Medical Journal 28(1): 239-244.

5. Celik H, Sapmaz E (2003) Use of a single preoperative dose of misoprostol is efficacious for patients who undergo abdominal myomectomy. Fertil Steril 79(5): 1207-1210.

6. Vercellino G, Erdemoglu E, Joe A, Hopfenmueller W, Holthaus B, et al. (2012) Laparoscopic temporary clippi ng of uterine artery during laparoscopic myomectomy. Arch Gynecol Obstet 286(5): 1181-1186.

7. Martin R, Monica Z, Renata H, Reitan R, William K, et al. (2015) How Do I Perform Temporary Occlusion of the Uterine Arteries During Laparoscopic Myomectomy? Gynecol Obstet 5(3): 1-4.

8. Chiang K, Hung C, Mu H, Yu C (2014) Reducing Blood Loss During Laparoscopic Myomectomy by Temporary Uterine Artery Clamping Using Bulldog Clamp. J Med Sci 34(4): 190-192.

9. Wang H, Liu M, Fuh L, Chao T, Chao C, et al. (2008) Laparoscopic uterine vessel occlusion in the treatment of women with symptomatic uterine myomas with and without adding laparoscopic myomectomy: 4-Year Results. J Minima Invasive Gynecol 15(6): 712-718.

10. Hasan M, Nasir A, Erum S (2014) Color Doppler Misoprostol Response Study (CDMRS): An Evaluation Tool for Patients Awaiting Myomectomy. Journal of Medical Ultrasound 22(2): 78-82.

11. Niroomand N, Hajiha S, Tabrizi NM, Ghajarzadeh M (2015) A single dose of misoprostol for reducing hemorrhage during myomectomy: a randomized clinical trial. Arch Gynecol Obstet 292(1): 1185-1189.

12. Kongnyuy E and Wiysonge CS (2011) Interventions to reduce haemorrhage during myomectomy for fibroids. Cochrane Database Syst Rev 15(8): CD005355.

13. Bae J, Chong O, Seong J, Hong G, Lee Y (2011) Benefit of uterine artery ligation in laparoscopic myomectomy. Fertil Steril 95: 775-78. abdominal myomectomy, Middle East Fertility Society Journal 19: 268273.

14. Holub Z, Jabor A, Lukac J, Kliment L, Urbanek S, et al. (2006) The effect of lateral uterine artery dissection on clinical outcomes in laparoscopic myomectomy: a prospective randomised study. Gynec Surg Endosc Imag All Tech 1: 253-258.

15. Alborzi S, Ghannadan E, Alborzi S, Alborzi M (2004) A comparison of combined laparoscopic uterine artery ligation and myomectomy versus laparoscopic myomectomy in treatment of symptomatic myoma. Fertil Steril 92(2): 742-747.

16. Altgassen C, Kuss S, Berger U, Löning M, Diedrich K, et al. (2006) Complications in laparoscopic myomectomy Surg Endosc 20(4): 614618.

17. Hanafi M (2014) Comparative study between robotic laparoscopic myomectomy and abdominal myomectomy, Middle East Fertility Society Journal 19: 268-273.

\section{Your next submission with Juniper Publishers will reach you the below assets}

- Quality Editorial service

- Swift Peer Review

- Reprints availability

- E-prints Service

- Manuscript Podcast for convenient understanding

- Global attainment for your research

- Manuscript accessibility in different formats

( Pdf, E-pub, Full Tsext, Audio)

- Unceasing customer service

Track the below URL for one-step submission

https://juniperpublishers.com/online-submission.php 